\title{
Importance of food in the control of inflammation in atopic dermatitis
}

\author{
MARIA ROTARU ${ }^{1,2}$, GABRIELA MARIANA IANCU ${ }^{1,2}$ and IRINA MIHAELA MATRAN ${ }^{3}$ \\ ${ }^{1}$ Department of Dermatology, Faculty of Medicine, Lucian Blaga University of Sibiu, 550169 Sibiu; \\ ${ }^{2}$ Clinic of Dermatology, County Clinical Emergency Hospital of Sibiu, 550245 Sibiu; ${ }^{3}$ Faculty of Pharmacy, \\ University of Medicine, Pharmacy, Science and Technology, 540142 Targu Mures, Romania
}

Received August 11, 2020; Accepted September 10, 2020

DOI: $10.3892 /$ etm. 2020.9336

\begin{abstract}
Patients that suffer from inflammatory diseases need to pay special attention to nutrition. For this reason, it is very important to change the approach of both health professionals and food industry specialists. There must be a close collaboration, starting from research, the development phase of foods for special nutrition states. Our primary objective was to identify foods or potential dietary ingredients, which efficacy in the treatment of atopic dermatitis had been scientifically demonstrated in vitro, in vivo and clinically. Furthemore, our perspective is presented regarding the research and development of foods for special nutritional states in atopic dermatitis. The PubMed database was analyzed for the period 2018-2020, as well as the European Legislation regarding the appropriate requirements for the composition and knowledge applicable to foods destined for use in special medical purposes. The search criteria were 'chronic dermatitis', 'atopic dermatitis', 'psoriasis', 'alternative treatments', 'natural treatments', 'complementary treatments', 'treatments for chronic dermatitis'. We also looked
\end{abstract}

Correspondence to: Dr Gabriela Mariana Iancu, Department of Dermatology, Faculty of Medicine, Lucian Blaga University of Sibiu, 2A Lucian Blaga Street, 550169 Sibiu, Romania

E-mail: mgabiancu@yahoo.com

Abbreviations: AD, atopic dermatitis; MALT1, Mucosa-associated lymphoid tissue lymphoma translocation protein 1 ; sCD, soluble form of cluster of differentiation; MnSOD, manganese superoxide dismutase; IL, interleukin; $\operatorname{Tr} 1$ cells, type 1 regulatory cells; HACCP, Hazard Analysis of Critical Control Points system; SCFAs, Short-chain fatty acids; Th1, T helper cells; TGF, transforming growth factor; IFN, interferon; RNA, messenger ribonucleic acid; MLN, mesenteric lymph node; GCs, goblet cells; GBA, glucocerebrosidase; Ig, immunoglobulin; MDC, macrophage-derived chemokines; CCL, chemokine ligand; GATA3, transcription factor; ROR $\gamma \mathrm{t}$, Retinoid-related orphan nuclear receptor $\gamma \mathrm{t}$

Key words: atopic dermatitis, foods for special nutritional states, inflammation, treatments for chronic dermatitis, complementary treatments for undesirable effects or side effects of the foods included in the research in order to treat atopic dermatitis. The results showed that prebiotics, probiotics and certain plant extracts had a high efficacy in controlling inflammation in atopic dermatitis. The food development research for special nutrition states (atopic dermatitis) involves a multidisciplinary team. We started with the establishment of the general objective and continued with the consultation of the PubMed, EMBASE and other databases, and with the in vitro, preclinical and/or clinical determination of the efficacy of new developed foods, that must be protected with patents. The development of foods for special nutrition states represents a solution for improving the quality of life of atopic dermatitis patients.

\section{Introduction}

Atopic dermatitis (AD) has a multifactorial pathology (immunological, genetical, environmental factors and skin barrier damage) with specific complex mechanisms $(1,2)$. There are certain foods that can trigger atopy, such as peanut allergy due to the MALT1 gene (3), chicken egg allergy (4), cow's milk or breast milk [due to changes in the sCD14 gene caused by environmental factors in today's society, that include the immune modulators from breast milk (5)] or fish (6). Also, the consumption of processed foods and/or energy drinks (7), antenatal exposure to some heavy metals (Plumb and Chrome) could determine the AD development after 24 months (8). Other substances that can cause AD are: Sodium monoglutamate (9), olive pollen (due to $\beta$-1, 3-glucanase rOle e9), allergen produces by Aspergillus (due to MnSOD rAsp f6 IgE) (10) or dust mites (11). So far, there are few dermato-endocrinological studies regarding the involvement of adipokines in the AD pathogenesis. Banihani et al (12), from Jordan, found that $38.7 \%$ of the patients with AD had been associated with some leptin genes that are polymorphic. The study showed that one of them (rs2167270) has the most important role.

Nutrition is one of the most important elements in improving the patients' quality of life in AD. There are preclinical studies that have shown that the systemic immunoregulatory effect of the probiotic bacterium Lactobacillus pentosus KF340 (LP340) (present in different fermented foods) was induced by interleukin (IL)-10, produced by $\operatorname{Tr} 1$ 
cells (13). Also, Bifidobacterium adolescentis and lactis, Lactobacillus sakei, acidophilus and casie and Longum are beneficial probiotic bacteria $(14,15)$. In order to suppress the allergic effect of pasteurized cow's milk, Abbring et al (16) treated it with alkaline phosphatase and obtained positive preclinical results.

The manufacture of safe food products for human health is performed in compliance with the rules of good hygiene and manufacturing norms (the HACCP principles). In translation, HACCP means: Risk analysis and determination of crucial control points, just like the production recipes specific to each economic agent or of the established/traditional recipes. The Regulation (EU) 218/2016 is available and presents the specific requirements in order to respect the composition and the information applicable to foods intended for particular medical purposes. According to the 4th paragraph, 'The composition of foods intended for special medical purposes may vary greatly depending on, among other things, the specific pathology, disorder or disease for which the diet is designed, the age of the patients and the place where they receive medical care or for the intended use of these products. In particular, foods intended for special medical purposes may be classified by composition into different categories, standard nutritional formula or an adapted nutritional formula, specific to a pathology, disorder or disease, or whether or not they constitute the only food source for the persons whom they are intended' (17).

The efficacy of the active substances (for which there is preclinical/clinical research presented in this paper) and the fact that they have been administered orally are the basis for developing foods to special nutritional states, in our case for AD.

The food industry operators who want to research and develop foods for special nutritional states, in our case for $\mathrm{AD}$, must form multidisciplinary teams that consist of food industry specialists and health professionals. Paragraph 3 of the aforementioned European Regulation, states that 'Foods for special medical purposes are developed in close cooperation with health professionals for the nutrition of patients with pathological disorders, suffering from a disorder or a specific disease or malnutrition due to these diseases which makes it impossible or very difficult to meet the nutritional needs of these patients through the consumption of other foods' (17). According to this paragraph 'For this reason, foods intended for special medical purposes should be used under medical supervision which can be provided with the assistance of other competent persons working in the health field' (17).

\section{Materials and methods}

The PubMed database was analyzed for the period 2018-2020. The search criteria were 'chronic dermatitis', 'atopic dermatitis', 'psoriasis' 'alternative treatments', 'natural treatments', 'complementary treatments', 'treatments for dermatitis chronic'. We also looked for undesirable or side effects related to foods, potential food ingredients and the action mechanisms of the analyzed foods. In the period 2018-2020 we identified 461 articles, of which 95 were preclinical researches and 265 clinical trials. Out of all the analyzed articles, only 31 were important for us, in order to achieve our objectives.
In this investigation we have tried to identify and to present foods and potential food ingredients for which there is scientific evidence and we formed a proposal the principles of research and food development for special nutritional states, for atopic dermatitis.

\section{Results}

The foods with systemic immunoregulatory effect used preclinically in the treatment of AD were determined. These are summarized in Table I. The foods and substances which efficacy has been clinically determined in vitro are presented in Tables II and III.

Considering the multidisciplinary character of the teams (medical, pharmaceutical and food industry) necessary to develop the food for special nutritional states (in our case for $\mathrm{AD}$ ), we propose the general principles underlying this process as indicated in Fig. 1.

The industrial protection of foodstuffs for special nutrition states is shown in Fig. 2.

\section{Discussion}

Preclinical research was performed over a large range of days from 7 to 77 days (Table I). The animal behavior did not change during the research. In these studies, the topical use of some substances (DNCB, DNFB and DEE) $(13,15,18,20-24,26)$, some nutrients (cow milk, red Korean ginseng) (16,21), UV radiations (25) and injections with Apigenin (19) could explain the appearance of skin lesions in AD.

Both in vivo and in vitro research has demonstrated the efficacy of prebiotics and probiotics [LP340 (13), L-92 (14), B. adolescentis (15), Cheongguk-jang (20), Duolac ATP (23), L. sakei WIKIM30 (26), Bacterial mixture of lactic acid (27)], plant extracts [Alnus sibirica (18), Korean red ginseng (21), Cinamamide (22)] and certain plant resources [ $\beta$-GdAP (24), CAPS (25), Korean Red Ginseng Extract (28), Strawberry seed extract (tiliroside) (30)] in alleviating the symptoms of atopic dermatitis (erythema, scaling/drying, erosion, edema and itching) (Tables I and II). This is due to the increase of IL-10, IL-12, CD40, CD80 and CD86, T cells spleen regulators, Firmicutes, Chaol index, colonic SCFAs, Th1, TGF- $\beta$, IL-2, IFN- $\gamma$, Galectin9 mRNA expression in MLN, GCs and GBA, IL- 6 and to the decrease of TGF- $\beta 1$, IgE, macrophage-derived chemokines (MDC/CCL22), IL-12 p40, apoptotic cells, B cells, $\mathrm{T}$ cells, $\mathrm{CD} 4^{+}, \mathrm{CD}^{+}, \mathrm{CD} 19^{+}, \mathrm{IL}-4$, IL-5, IL-13, GATA3 and RoR $\gamma \mathrm{t}$ mRNA expression.

There are meta-analyses that sustain the beneficial anti-inflammatory effects of topical Janus kinase inhibitors in some inflammatory diseases (psoriasis, atopic dermatitis) (31). An other attractive therapy for AD is the topical phosphodiesterase inhibitors that act by reducing the release of proinflammatory cytokines (32).

The efficacy of Korean red ginseng in the treatment of $\mathrm{AD}$ has been demonstrated preclinically and clinically. This product determines the growth of: Hydration degree, lipid layers, angiogenesis and neovascularization, epithelization, fibroblast activity, collagen accumulation (21) and IGA (28) (Tables I and II). It also determines the decrease of skin regeneration time, severity of the disease, EASI score, 


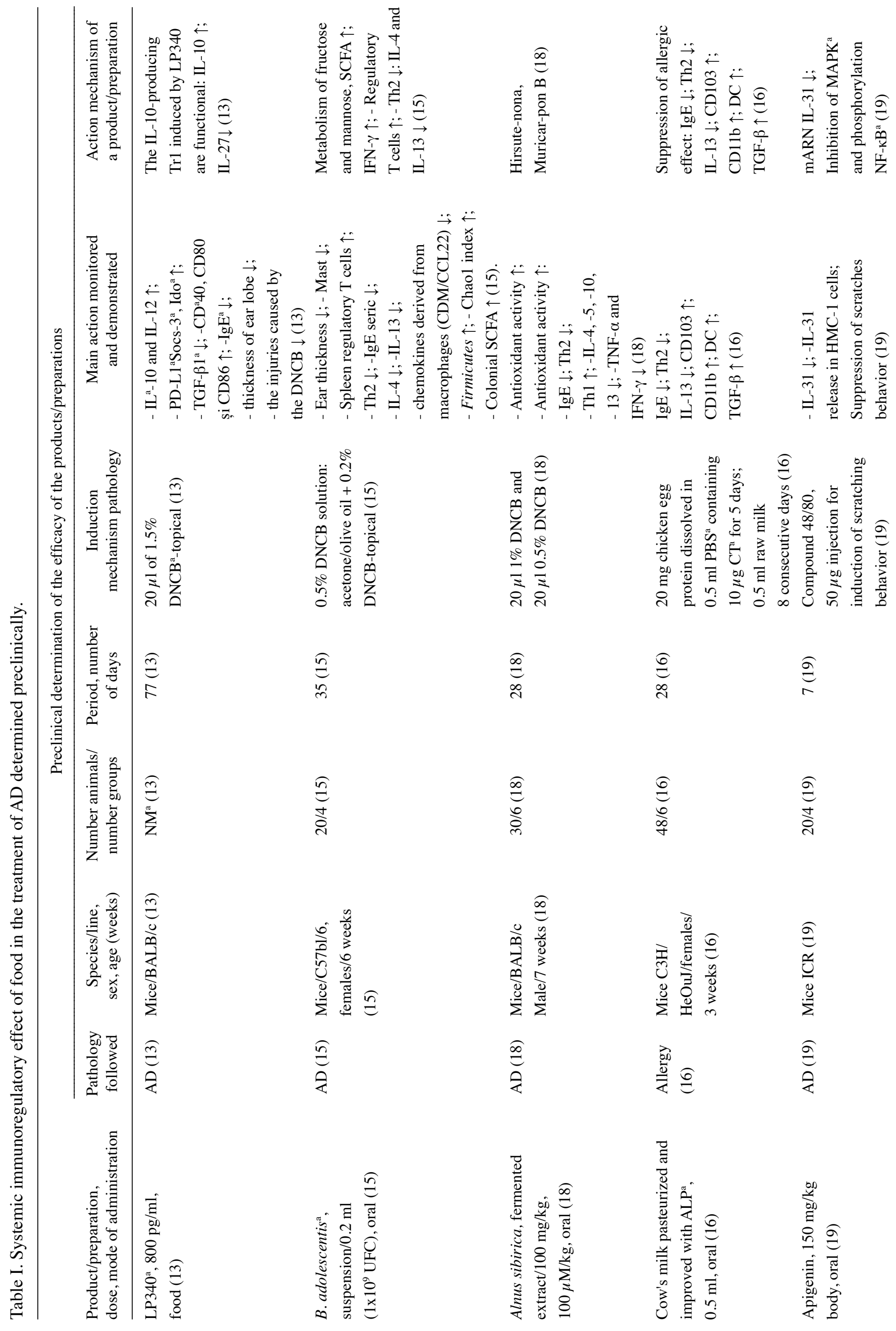




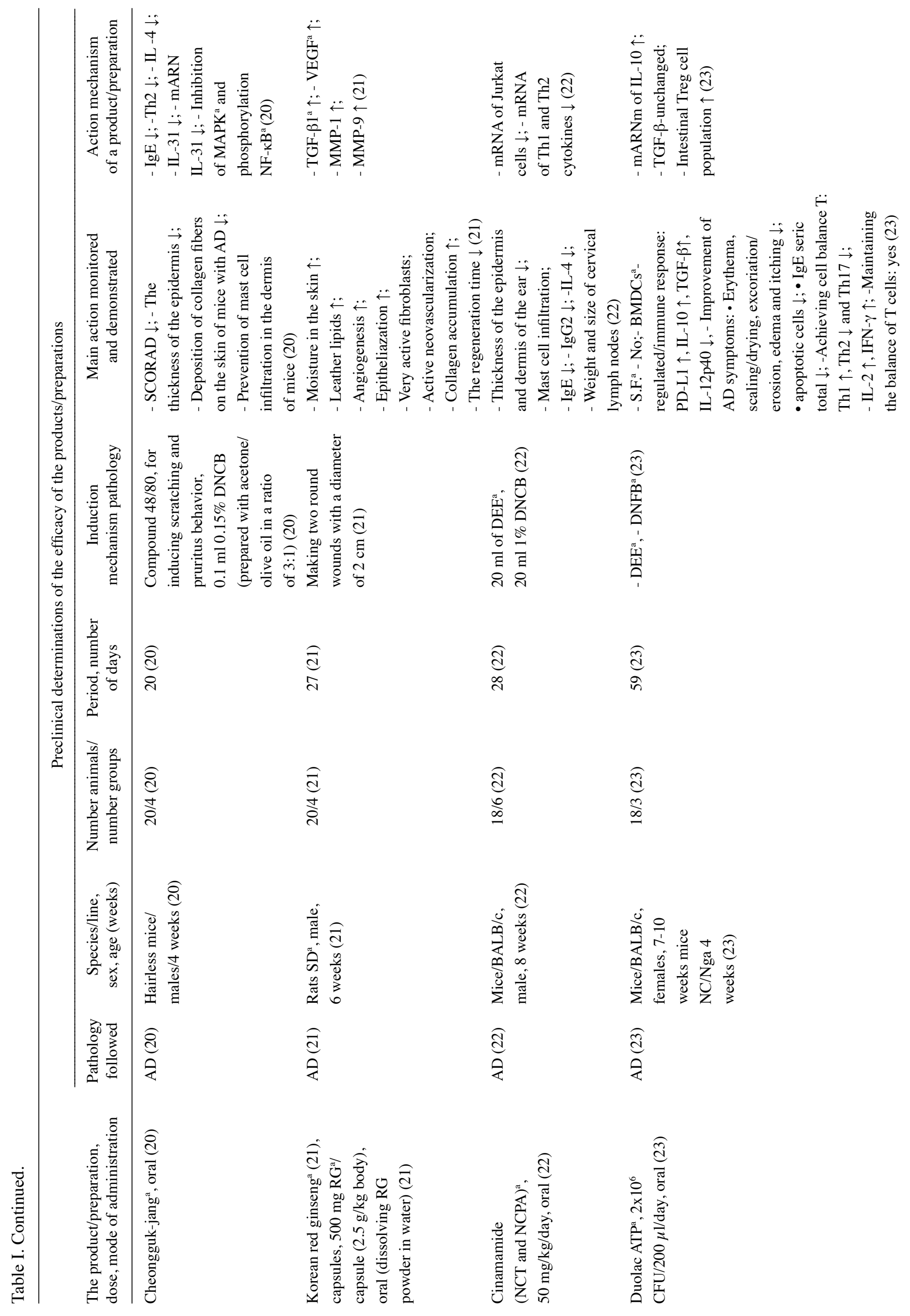




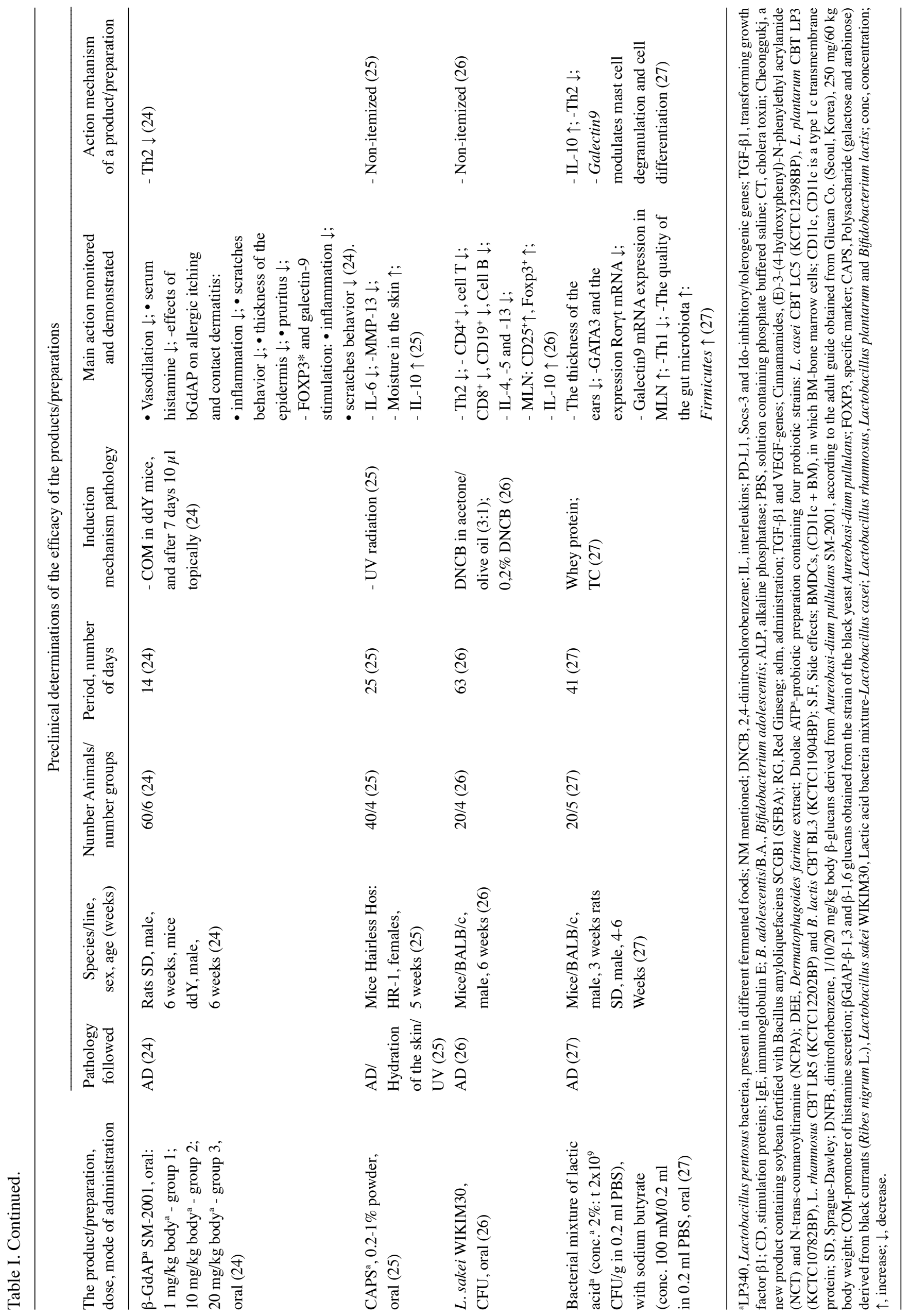



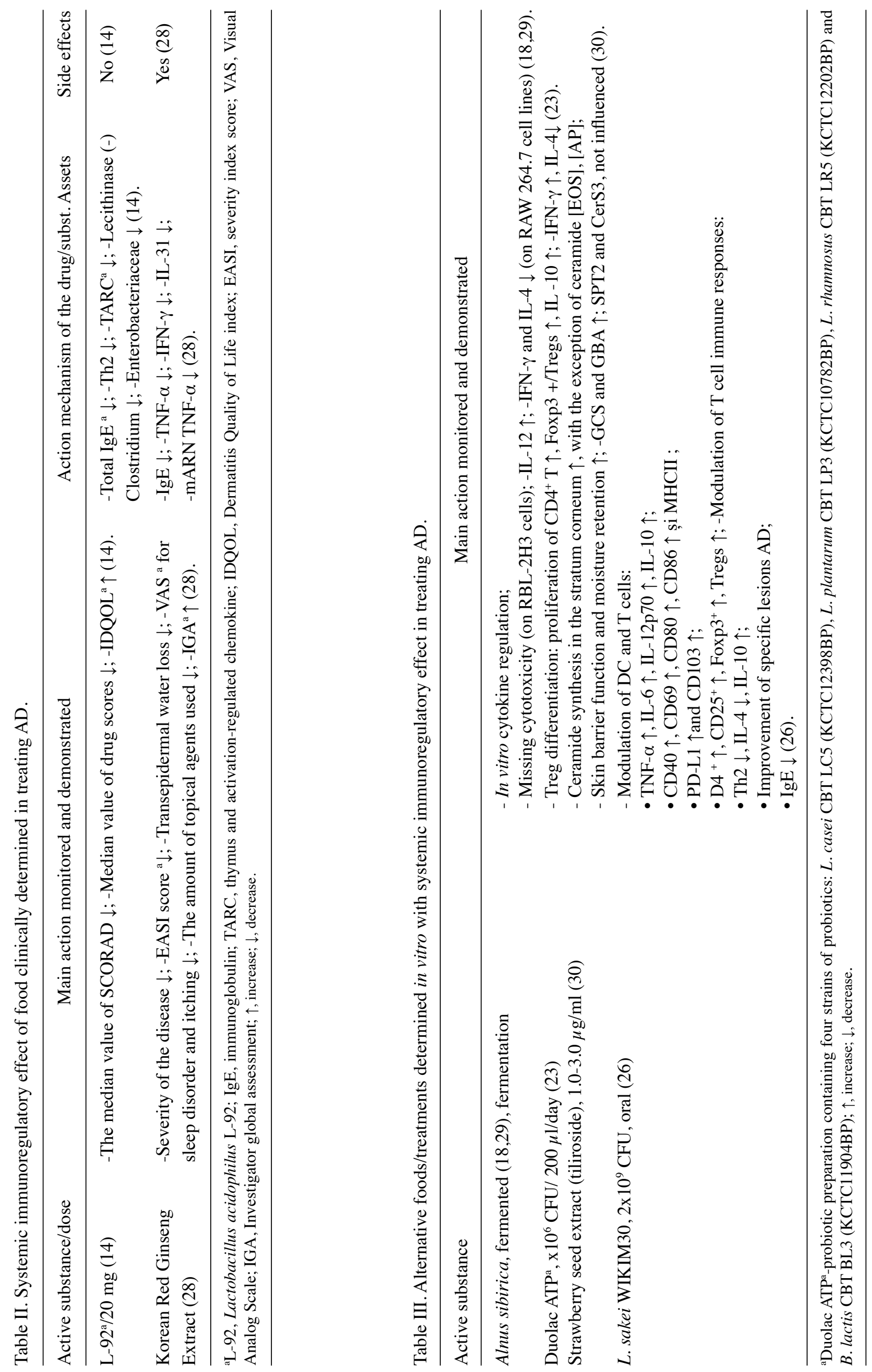

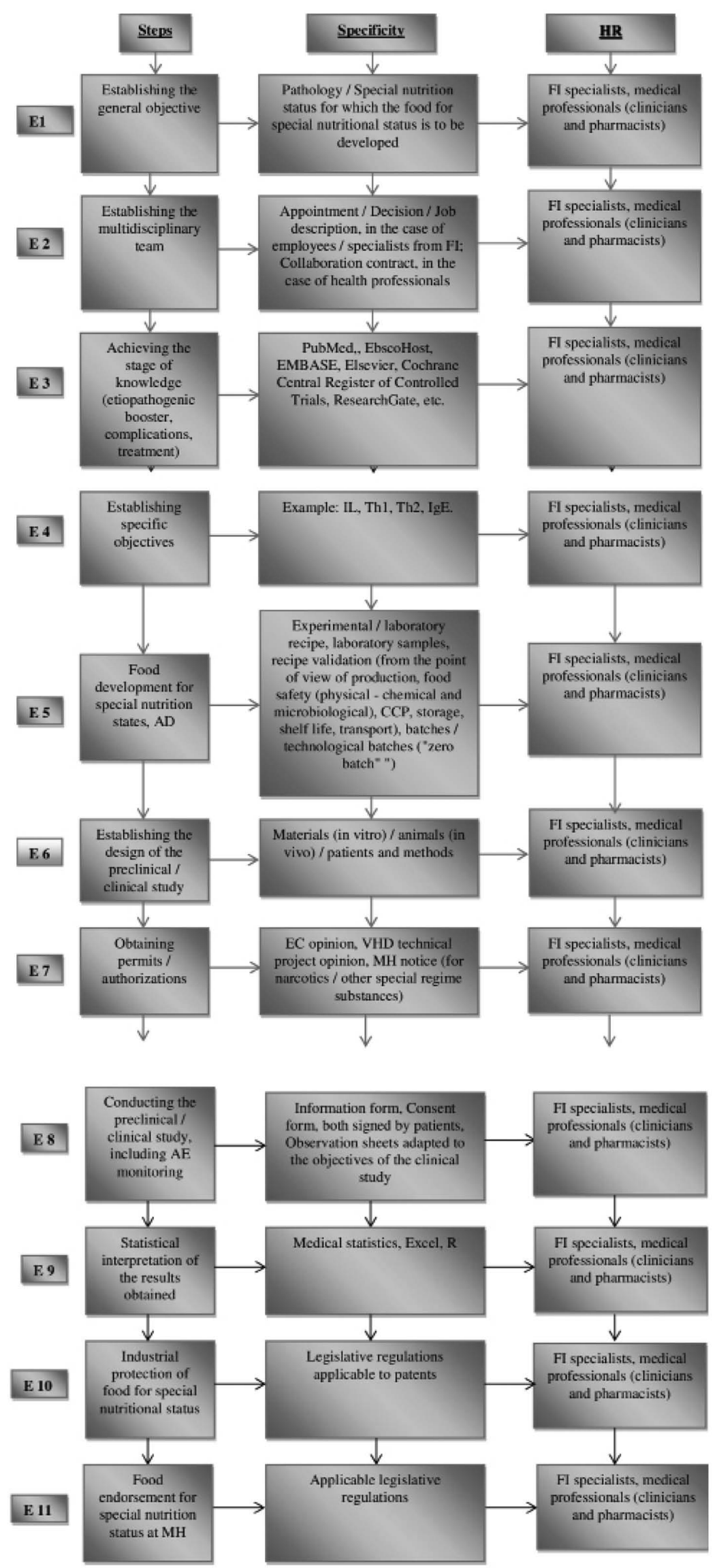

Figure 1. Food development for special nutrition states. General principles. E, stage in the research process - development of foods for special nutrition states, in vitro/preclinical/clinical evaluation and their approval to the MH; HR, human resources; FI, food industry; IL, interleukins; Th, T helper cells; IgE, immunoglobulin E; CCP, critical control point (it is essential for food safety. It is the stage in which a control measure can be used to prevent or eliminate a food safety hazard or to reduce it to an acceptable level); AD, atopic dermatitis; EC, Ethics Committee; VHD, Veterinary Health Department; MH, Ministry of Health; R, program of medical statistics; AE, adverse events. 


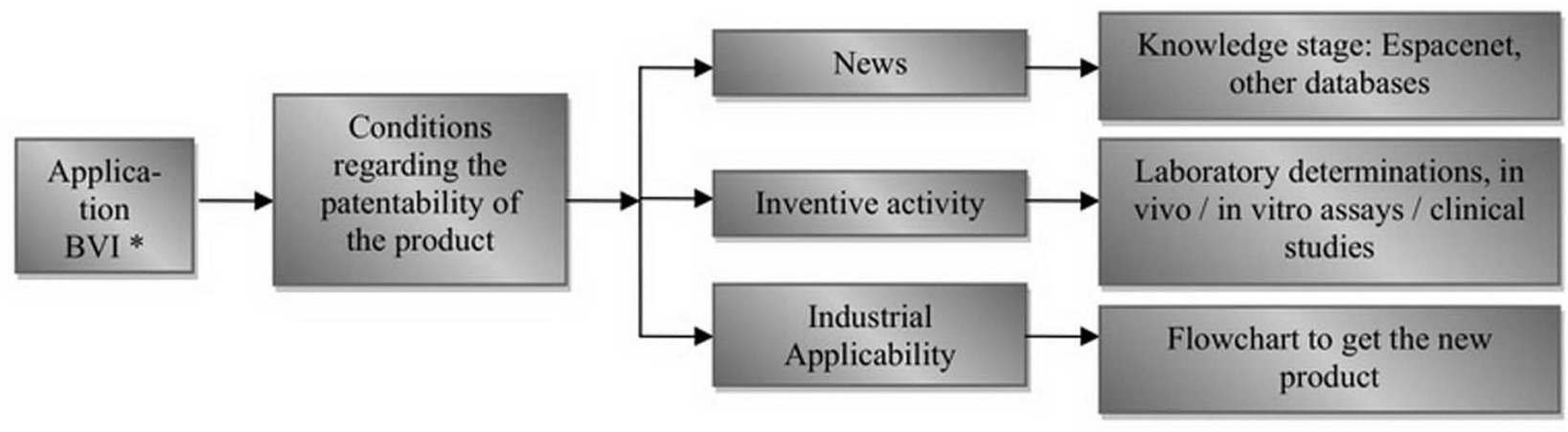

*BVI-Patent of invention

Figure 2. Industrial protection of food stuffs for special nutrition states. PI, patent of invention.

transepidermal water loss, visual analog scale, SCORAD (that quantified also the itching and lack of sleep) and the number of topical agents used (28).

From a legislative point of view, we consider that the European authorities (Commissions, Medicine Agency and Food Safety Authority) and national authorities (the Ministry of Health), should issue a common guide for all the countries in the EU. This guide must provide the principles of the development of food for special nutritional states, such as: The etiopathogenic booster, the diagnostic problems, the diagnosis of complications, the treatment (hygienic-dietary regimens, drug treatment). It should complete the legislative regulations in order to obtain the Notice of the Ethics Commission for conducting preclinical/clinical studies and also for foods for special nutritional states. This notice is not only for drugs and/or dietary supplements but also for the nutrivigilance system that identifies and monitors the side effects caused by the new foods for special nutritional states, similar to the existing pharmacovigilance system.

The development of foods for special medical purposes requires multidisciplinary knowledge and multiple resources. Out of all the resources, time is the most expensive one because the determination of the efficacy of these products takes a lot of time.

To develop the foods for special nutritional states we need to know the etiopathogeny of the disease, the symptomatology and the pharmacological principles (Fig. 1).

The top management of food factories that want to manufacture food for special nutritional conditions, must have multidisciplinary teams, specialized in research and development of these products, or collaborate with health professionals. The principles proposed in Fig. 1 are also valid for the development of food supplements.

Industrial protection (obtaining the invention patent) is a long-term process. It is based on the verification of the stage of knowledge (including patents filed worldwide), physico-chemical and preclinical/clinical analyzes. Also, it is necessary to know the advantages and disadvantages of the new developed food for special nutritional status in comparison with others existing patents (Fig. 2).

In conclusion, the development of foods for special nutrition states represents a solution for improving the quality of life of atopic dermatitis patients.

\section{Acknowledgements}

Not applicable.

Funding

No funding was received.

\section{Availability of data and materials}

The datasets used and/or analyzed during the current study are available from the corresponding author on reasonable request.

\section{Authors' contributions}

MR contributed in the conception and design of the study, analysis and interpretation of the data, manuscript drafting and critical revision of the manuscript for important intellectual content. GMI was responsible for the analysis and interpretation of the data, manuscript drafting and design, and critical revision of the manuscript for important intellectual content. IMM contributed in the conception and design of the study, data acquisition, analysis and interpretation of the data, manuscript drafting and design, and critical revision of the manuscript for important intellectual content. All authors read and approved the final manuscript.

\section{Ethics approval and consent to participate}

Not applicable.

\section{Patient consent for publication}

Not applicable.

\section{Competing interests}

The authors declare that they have no competing interests and they have no financial relationships to disclose.

\section{References}

1. Rotaru M, Ionescu A, Rotaru BI and Iancu GM: Etiopathogenic and therapeutic considerations in atopic dermatitis. Acta Medica Transilvanica 24: 34-38, 2019. 
2. Solomon I, Ilie MA, Draghici C, Voiculescu VM, Caruntu C, Boda D and Zurac S: The impact of lifestyle factors on evolution of atopic dermatitis: An alternative approach. Exp Ther Med 17: 1078-1084, 2019

3. Rudman Spergel AK and Togias A: Observational human studies in allergic diseases: Design concepts and highlights of recent National Institute of Allergy and Infectious Diseases-funded research. Curr Opin Allergy Clin Immunol 20: 208-214, 2020.

4. Grimshaw KEC, Roberts G, Selby A, Reich A, Butiene I, Clausen M, Dubakiene R, Fiandor A, Fiocchi A, Grabenhenrich LB, et al: Risk factors for Hen's Egg allergy in Europe: EuroPrevall birth cohort. J Allergy Clin Immunol Pract 8: 1341-1348.e5, 2019.

5. Fikri B, Tani Y, Nagai K, Sahara M, Mitsuishi C, Togawa Y, Nakano T, Yamaide F, Ohno H and Shimojo N: Soluble CD14 in breast milk and its relation to atopic manifestations in early infancy. Nutrients 11: 2118, 2019.

6. Yuan M, Tan M, Moore D, Shen S, Qiu X, Thomas GN and Cheng K: Timing of Cow's Milk or Cow's milk formula introduction to the infant diet and atopic risk in children: A systematic review and meta-analysis. Clin Rev Allergy Immunol 59: 46-60, 2020.

7. Cho SI, Lee H, Lee DH and Kim KH: Association of frequent intake of fast foods, energy drinks, or convenience food with atopic dermatitis in adolescents. Eur J Nutr: Dec 10, 2019 (Epub ahead of print). doi: 10.1007/s00394-019-02157-4.

8. Kim J, Kim S, Woo SY, Chung JY, Hong YS, Oh SY, Choi SJ, Oh SY, Kim KW, Shin YH, et al: Prenatal exposure to lead and chromium is associated with IL-13 levels in umbilical cord blood and severity of atopic dermatitis: COCOA atudy. Immune Netw 19: e42, 2019.

9. Zanfirescu A, Ungurianu A, Tsatsakis AM, Nitulescu GM, Kouretas D, Veskoukis A, Tsoukalas D, Engin AB, Aschner M and Margină D: A review of the alleged health hazards of monosodium glutamate. Compr Rev Food Sci Food Saf 18: 1111-1134, 2019.

10. Scala E, Abeni D, Guerra EC, Pirrotta L, Locanto M, Meneguzzi G, Giani M, Russo G and Asero R: $\beta$-1,3-glucanase rOle e 9 and MnSOD rAsp f 6 IgE reactivity are the signature of atopic dermatitis in the Mediterranean area.Clin Exp Allergy 50: 487-498, 2020

11. Emran H, Chieng CSE, Taib S and Cunningham AC: House dust mite sensitisation and association with atopic dermatitis in Brunei: Allergen sensitization and allergic disease in Brunei. Clin Transl Allergy 9: 65, 2019.

12. Banihani SA, Elmadhoun RA, Khabour OF and Alzoubi KH: The rs2167270 polymorphism of leptin gene is associated with atopic dermatitis. Dermatoendocrinol 10: e1454191, 2018.

13. Kim JE, Sharma A, Sharma G, Lee SY, Shin HS, Rudra D and Im SH: Lactobacillus pentosus modulates immune response by inducing IL-10 producing Tr1 cells. Immune Netw 19: e39, 2019

14. Nakata J, Hirota T, Umemura H, Nakagawa T, Kando N, Futamura M, Nakamura Y and Ito K: Additive effect of Lactobacillus acidophilus L-92 on children with atopic dermatitis concomitant with food allergy. Asia Pac Allergy 9: e18, 2019.

15. Fang Z, Li L, Zhao J, Zhang H, Lee YK, Lu W and Chen W: Bifidobacteria adolescentis regulated immune responses and gut microbial composition to alleviate DNFB-induced atopic dermatitis in mice. Eur J Nutr: Nov 30, 2019 (Epub ahead of print). doi: 10.1007/s00394-019-02145-8.

16. Abbring S, Ryan JT, Diks MA, Hols G, Garssen J and van Esch BC: Suppression of food allergic symptoms by raw cow's milk in mice is retained after skimming but abolished after heating the Milk-A promising contribution of alkaline phosphatase. Nutrients 11: 1499, 2019.

17. Official Journal of the European Union: Commission Delegated Regulation (EU) 2016/128 of 25 September 2015 supplementing Regulation (EU) No 609/2013 of the European Parliament and of the Council as regards the specific compositional and information requirements for food for special medical purposes. Document 32016RO128, 2016. http://data.europa.eu/eli/reg_del/2016/128/oj
18. Yin J, Yoon SH, Ahn HS and Lee MW: Inhibitory activity of allergic contact dermatitis and atopic dermatitis-like skin in $\mathrm{BALB} / \mathrm{c}$ mouse through oral administration of fermented barks of Alnus sibirica. Molecules 23: 450, 2018.

19. Che DN, Cho BO, Shin JY, Kang HJ, Kim JS, Oh H, Kim YS and Jang SI: Apigenin inhibits IL-31 cytokine in human mast cell and mouse skin tissues. Molecules 24: 1290, 2019.

20. Cho BO, Shin JY, Kim JS, Che DN, Kang HJ, Jeong DY and Jang SI: Soybean fermented with Bacillus amyloliquefaciens (Cheonggukjang) ameliorates atopic dermatitis-like skin lesion in mice by suppressing infiltration of mast cells and production of IL-31 cytokine. J Microbiol Biotechnol 29: 827-837, 2019.

21. Park KS and Park DH: The effect of Korean Red Ginseng on full-thickness skin wound healing in rats. J Ginseng Res 43: 226-235, 2019.

22. Choi EJ, Ryu YB, Tang Y, Kim BR, Lee WS, Debnath T, Fan M, Kim EK and Lee HS: Effect of cinnamamides on atopic dermatitis through regulation of IL-4 in $\mathrm{CD}^{+}{ }^{+}$cells. J Enzyme Inhib Med Chem 34: 613-619, 2019.

23. Kim HW, Hong R, Choi EY, Yu K, Kim N, Hyeon JY, Cho KK, Choi IS and Yun $\mathrm{CH}$ : A probiotic mixture regulates $\mathrm{T}$ cell balance and reduces atopic dermatitis symptoms in mice. Front Microbiol 9: 2414, 2018

24. Kim IS, Lee SH, Kim JA, Yu DY, Hong YH, Kim JY, Lim JM, Lee SS, Yun CH, Choi IS and Cho KK: Effect of oral administration of $\beta$-glucans derived from Aureobasidium pullulans SM-2001 in model mice and rat with atopic dermatitis-like phenotypes. Food Sci Biotechnol 27: 1185-1192, 2018

25. Ashigai H, Komano Y, Wang G, Kawachi Y, Sunaga K, Yamamoto R, Takata R and Yanai T: Orally administered polysaccharide derived from blackcurrants (Ribes nigrum L.) improves skin hydration in ultraviolet-irradiated hairless mice. J Nutr Sci Vitaminol (Tokyo) 64: 301-304, 2018.

26. Kwon MS, Lim SK, Jang JY, Lee J, Park HK, Kim N, Yun M, Shin MY, Jo HE, Oh YJ, et al: Lactobacillus sakei WIKIM30 ameliorates atopic dermatitis-like skin lesions by inducing regulatory T cells and altering gut microbiota structure in mice. Front Immunol 9: 1905, 2018.

27. Kim JA, Kim SH, Kim IS, Yu DY, Kim SC, Lee SH, Lee SS, Yun $\mathrm{CH}$, Choi IS and Cho KK: Anti-inflammatory effects of a mixture of lactic acid bacteria and sodium butyrate in atopic dermatitis murine model. J Med Food 21: 716-725, 2018.

28. Kim H, Park CW and Cho SH: The beneficial effect of Korean red ginseng extract on atopic dermatitis patients: An 8 weeks open, noncomparative clinical study. Ann Dermatol 30: 304-308, 2018.

29. Wang HS, Hwang YJ, Yin J and Lee MW: Inhibitory effects on no production and DPPH radicals and NBT superoxide activities of Diarylheptanoid isolated from enzymatically hydrolyzed ehthanolic extract of Alnus sibirica. Molecules 24: 1938, 2019.

30. Takeda S, Shimoda H, Takarada T and Imokawa G: Strawberry seed extract and its major component, tiliroside, promote ceramide synthesis in the stratum corneum of human epidermal equivalents. PLoS One 13: e0205061, 2018.

31. Hosking AM, Juhasz M and Mesinkovska NA: Topical Janus kinase inhibitors: A review of applications in dermatology. Am Acad Dermatol 79: 535-544, 2018.

32. Yang H, Wang J, Zhang X, Zhang Y, Qin ZL, Wang H and Luo XY: Application of topical phosphodiesterase 4 inhibitors in mild to moderate atopic dermatitis. JAMA Dermatol 155: 585-593, 2019. 